\title{
Degradation of Diclofenac in Molecularly Imprinted Polymer Submicron Particles by UV Light Irradiation and $\mathrm{HCl}$ Acid Treatment
}

\author{
Mohammad Hassanzadeh-Khayyat ${ }^{1}$, Edward P. C. Lai $^{2 *}$, Kerim Kollu ${ }^{3}$, Banu Ormeci ${ }^{3}$ \\ ${ }^{1}$ Pharmaceutical Sciences Research Center, Department of Pharmaceutical Chemistry, \\ University of Medical Sciences, Mashhad, Iran \\ ${ }^{2}$ Department of Chemistry, Carleton University, Ottawa, Canada \\ ${ }^{3}$ Department of Civil and Environmental Engineering, Carleton University, Ottawa, Canada \\ E-mail: edward_lai@carleton.ca
}

Received July 2, 2011; revised August 3, 2011; accepted September 2, 2011

\begin{abstract}
A new molecularly imprinted polymer (MIP) was synthesized by precipitation polymerization using diclofenac (DFC) as a template. Binding characteristics of the MIP particles were evaluated by equilibrium binding experiments. DFC-MIP aqueous suspension and non-imprinted polymer (NIP) suspension were exposed to monochromatic UV light $(253.7 \mathrm{~nm})$ from low-pressure mercury lamps. UV-visible spectrophotometry (especially absorbance at $276 \mathrm{~nm}$ ) showed that the DFC inside MIP particles degraded completely. After DFC-MIP suspension exposure to UV light the particles were completely regenerated after washing with water at least six times. The regenerated MIP particles rebounded considerable amount of DFC (approximately $88 \%$ removal of $44 \mathrm{ppm}$ DFC). The stability of DFC was examined in the presence of various concentrations of hydrochloric acid $(0.025$ to $125 \mathrm{mM})$. Experimental results showed that degradation of DFC was efficient, depending on the acid concentration as well as the treatment time. However, there was no re-binding of DFC by the MIP particles after $\mathrm{HCl}$ treatment (and DDW washing) when exposed to DFC for 24 hours.
\end{abstract}

Keywords: Diclofenac, Molecularly Imprinted Polymer, Submicron Particles, UV Irradiation, Degradation, Acid Treatment

\section{Introduction}

Many pharmaceuticals along with their metabolites have been detected in environmental water samples. Due to the high persistence and low biodegradability of these compounds, as well as their potential impact on human health and the environment even at low concentration levels, they have elicited great concern about ecotoxicity [1-3]. Diclofenac, ibuprofen and propranolol are three widely used pharmaceuticals that are prescribed and sold in large quantities. Diclofenac (DFC), derived from benzene acetic acid (Scheme 1), is a non-steroidal anti-inflammatory drug (NSAID) of cyclooxygenase inhibitor [4-7]. It is used in the treatment of rheumatoid arthritis, osteoarthritis, and ankylosing spondylitis. It is also used for the symptomatic relief of low back pain, post operative pain, musculoskeletal injuries and chronic pain as- sociated with cancer [8]. The sodium or potassium salts are soluble in water for oral administration. DFC escapes conventional urban wastewater treatment plants because of its resistance to biodegradation. Advanced processes like ozonation and ultrasonolysis can be employed for<smiles>N#Cc1cccc(Cl)c1Nc1ccccc1CC(=O)O</smiles>

Scheme 1. Molecular structure of sodium (or potassium) DFC, a salt of 2-[(2,6-dichlorophenyl)amino] phenyl acetic acid. 
the removal of recalcitrant DFC from water matrices. The synergy observed in the combined schemes, however, led to only $40 \%$ mineralization for $40 \mathrm{~min}$ treatment [9]. Therefore it is frequently found in treated effluents, lakes and rivers [10]. Exposure assessment of DFC based on the overall load was obtained in nine effluents of sewage treatment plants, with concentrations up to $2.2 \mu \mathrm{g} / \mathrm{L}$ [11]. Already at significant environmental concentration levels, its harmful effects to different aquatic organisms have been demonstrated. Mussels exposed to $10,000 \mu \mathrm{g} / \mathrm{L}$ of DFC had a significantly lower scope for growth and byssus strength [12]. The uptake reached concentrations two orders of magnitudes higher than found in sewage treatment plant effluents. Veterinary use of DFC in South Asia resulted in the high mortalities of three vulture species to the category of global extinction risk [13]. Vultures are exposed to DFC when scavenging on livestock treated with the drug shortly before death. DFC causes kidney damage, increased serum uric acid concentrations, visceral gout, and death. It is largely regarded as one of the most devastating environmental toxicant in recent times [14].

Calza et al. studied the photocatalytic transformation of DFC, under simulated solar irradiation using $\mathrm{TiO}_{2}$ suspensions as catalyst, to assess the decomposition of DFC [15]. Hofmann et al. investigated the degradation of DFC in water by heterogeneous catalytic oxidation with $\mathrm{H}_{2} \mathrm{O}_{2}$ [16]. Ghauch et al. investigated the aqueous removal of DFC by micrometric iron particles $\left(\mathrm{Fe}^{0}\right)$ and amended $\mathrm{Fe}^{0}\left(\operatorname{metal}^{0}\left(\mathrm{Fe}^{0}\right)\right)$ under oxic and anoxic conditions. Oxidative and reductive DFC transformation products were identified [17]. Achilleos et al. reported that DFC decomposition was affected adversely by the amount of catalyst, complexity of water matrix, initial DFC concentrations, and $\mathrm{H}_{2} \mathrm{O}_{2}$ to DFC concentration ratio [18]. Laera et al. demonstrated that integrating a membrane bioreactor and $\mathrm{TiO}_{2} / \mathrm{UV}$ photocatalysis reactor could be a promising technology to treat pharmaceutical wastewater (characterized by simultaneous presence of biodegradable and refractory/inhibitory compounds) [19]. Madhaven et al studied the sonolytic, photocatalytic and sonophotocatalytic degradation of DFC using three photocatalysts $\left(\mathrm{TiO}_{2}, \mathrm{ZnO}\right.$ and $\left.\mathrm{Fe}-\mathrm{ZnO}\right)$. The sonophotocatalytic degradation using $\mathrm{TiO}_{2}$ under UV-visible radiation showed a slight synergistic enhancement in the degradation of the parent compound, but a detrimental effect was observed for the mineralization process [20].

There have been few studies into whether microbial consortia (in activated sludge) can degrade all pharmaceuticals when exposed to pandemic-scale doses [21,22]. Degradation of DFC sodium was assessed by MarcoUrrea et al. using the white rot fungus Trametes versicolor. Almost complete DFC removal ( $\geq 94 \%)$ occurred during the first hour when the drug was added at relatively high $\left(10 \mathrm{mg} \cdot \mathrm{L}^{-1}\right)$ and environmentally relevant low (45 $\mu \mathrm{g} \cdot \mathrm{L}^{-1}$ ) concentrations in a defined liquid medium [23]. Zhang and Geißen produced crude lignin peroxidase from a white rot fungus (Phanerochaete chrysosporium) that completely degraded DFC at $\mathrm{pH} 3.0-4.5$ and 3 - 24 ppm $\mathrm{H}_{2} \mathrm{O}_{2}$, under increased temperature with the addition of veratryl alcohol [24]. Degradation by ultrasonic irradiation is an alternative that eliminates DFC from water without the addition of chemicals or fungi [25]. Hartmann et al investigated the sonolysis of DFC in water at ultrasound frequencies of $24-850 \mathrm{kHz}$. Catalysts (especially $\mathrm{TiO}_{2}$ ) increased the rate of degradation, decreasing the concentration of DFC from $100 \%$ to $16 \%$ within $30 \mathrm{~min}$ [26]. Güyer and Ince studied the degradation of DFC by ultrasound with the addition of non-reactive iron superoxide nanoparticles. The initial concentration, $\mathrm{pH}$ and frequency of operation that rendered maximum degradation were $30 \mu \mathrm{M}, 3.0$ and $861 \mathrm{kHz}$, respectively [27]. The remarkably high efficacy $(42 \mu \mathrm{M} /$ $\mathrm{mg} / \mathrm{hr}$ ) was attributed to the synergy of nanotechnology and ultrasound, combining the effects of massive surface area, excess cavitation nuclei, enhanced mass transfer and continuous cleaning of the metal surface. However, more research is still needed for the development of microbial, physical, and chemical methods for the degradation and removal of DFC after their discharge in the environment.

Controlled release of the sodium salt of DFC had previously been studied by using low molecular weight poly (lactic acid) as a matrix, which could be regenerated for reuse after treatment with methanol/acetic acid $(9: 1, \mathrm{v} / \mathrm{v})$ [28]. Polyvinyl alcohol and polyacrylic acid had also been cross-linked with glutaraldehyde to form microspheres for delivery of DFC sodium to the intestine [29]. A molecularly imprinted polymer (MIP) was synthesized by precipitation polymerization using $\mathrm{DFC}$ as a template [30]. Binding characteristics of the MIP were evaluated using equilibrium binding experiments. Compared to the non-imprinted polymer (NIP), the MIP showed an outstanding affinity towards DFC in an aqueous solution with a binding site capacity $\left(Q_{\max }\right)$ of $325 \mathrm{mg} / \mathrm{g}$ and a dissociation constant $\left(K_{\mathrm{d}}\right)$ of $4 \mathrm{mg} / \mathrm{L}$. The feasibility of removing DFC from natural water by the MIP was demonstrated by using spiked river water. Effects of $\mathrm{pH}$ and humic acid on the selectivity and adsorption capacity of MIP were evaluated. MIP had better selectivity and higher adsorption efficiency for DFC as compared to that of powdered activated carbon (PAC). In addition, MIP reusability was demonstrated for at least 12 repeated cycles without significant loss in performance, which is a definite advantage over single-use activated carbon. These results evidenced the advantages of MIPs for treating 
pharmaceutical wastewater and similar industrial effluents.

The aim of this study was to synthesize a new MIP using DFC as the template, and evaluate the binding characteristics of DFC-MIP particles. Degradation of DFC inside the particles by exposure to UV light, as well as by treatment with hydrochloric acid, was examined. Finally, the regeneration of MIP particles was explored, and rebinding of DFC was assessed.

\section{Experimental}

\subsection{Materials}

Pure DFC sodium salt (CAS \# 15307-76-6) was purchased from Sigma-Aldrich (St. Louis, MO, USA). Methacrylic acid (MAA), ethylene glycol dimethacrylate (EGDMA) and 2,2'-azobisisobutyronitrile (AIBN) were all obtained from Sigma-Aldrich (Oakville, ON, Canada). HPLC grade methanol, acetonitrile and acetone as well as hydrogen peroxide $(35 \% \mathrm{w} / \mathrm{w}$ per hydrol) were purchased from Caledon (Georgetown, ON, Canada). Hydrochloric acid (reagent grade) was purchased from Anachemia (Montreal, QC, Canada). 18-M $\Omega . c m$ distilled deionized water (DDW) was obtained from a Millipore Milli-Q water system (Bedford, MD, USA).

\subsection{Molecularly Imprinted Polymer and Non-Imprinted Polymer Particles}

The synthesis of DFC-molecularly imprinted polymer (DFC-MIP) and non-imprinted polymer (NIP) submicron particles was based on a previously established method except for the template [31]. MAA (carrying a complementary functional group) forms a complex with DFC (the template molecule) via hydrogen bonding and electrostatic interactions in a porogen solvent (acetone/ acetonitrile, 1:3 v/v). EGDMA and AIBN were then added, followed by sonication for 5 minutes, to obtain a homogenous solution. Deoxygenation by pure nitrogen gas for another 5 minutes was imperative. Finally, the vial was sealed and placed in a $60^{\circ} \mathrm{C}$ thermostatted water bath for 24 hours to produce MIP particles. Similarly NIP particles were prepared, only without any template molecule. The DFC-MIP and NIP particles in suspension were separately placed in $15-\mathrm{mL}$ polypropylene tubes (Greiner Bio-One, Frickenhausen, Germany), and then spun by a centrifuge (Hamilton Bell VanGuard Centrifuge, Montvale, NJ, USA) for $60 \mathrm{~min}$ at $4000 \mathrm{rpm}$ to help remove the supernatants. A stock suspension of the particles was prepared in DDW, from which different working concentrations $(\mathrm{mg} / \mathrm{mL})$ were prepared in DDW as needed. All aqueous suspensions of DFC-MIP and
NIP particles were ultra-sonicated (Branson 2510, Danbury, CT, USA) for $10 \mathrm{~min}$ before use.

\subsection{Particle Size Measurements by Dynamic Light Scattering (DLS)}

The MIP particles were suspended in $10 \mathrm{M} \mathrm{KNO}_{3}$ at a concentration of $40 \mathrm{mg} / \mathrm{mL}$. The suspension was sonicated for $15 \mathrm{~min}$ before ten measurements were run on a NanoDLS particle size analyzer (Brookhaven Instruments, Holtsville, NY, USA). The analyzer had been calibrated by $92 \pm 4 \mathrm{~nm}$ Nanosphere ${ }^{\mathrm{TM}}$ size standards (Duke Scientific, Palo Alto, CA, USA).

\subsection{UV Absorption Measurements}

The absorption spectra of DFC standard solutions and DFC-MIP suspensions were monitored using a Cary 3 Varian UV-visible spectrophotometer (Varian, Mulgrave, Australia) equipped with the Carydiag software. Absorbance was measured at the wavelength of maximum absorption in the $\mathrm{UV}$ region $(276 \mathrm{~nm})$ to determine the $\%$ degradation of DFC.

\subsection{UV Exposure of DFC}

The UV irradiation setup consisted of four low-pressure mercury lamps (Phillips UV-C germicidal lamps, TUV 15W/G15 T8, Somerset, NJ, USA) emitting monochromatic ultraviolet light at $253.7 \mathrm{~nm}$. UV irradiation experiments were conducted according to the procedure previously outlined [32], and the samples were exposed to an average UV intensity of either 300 or $600 \mathrm{~mJ} / \mathrm{cm}$. The average intensity was determined by incorporating the incident UV light intensity, petri factor (ratio of the average surface intensity to the centre intensity), and UV 254 absorbance and depth of the sample, using an integration of the Beer-Lambert law [33]. The UV-254 absorbance of each sample was measured by a UV-visible spectrophotometer (Varian Model Cary 100 BIO, Victoria, Australia). The $6.5-\mathrm{cm}$ Petri dishallowed for a sample solution depth of $0.6 \mathrm{~cm}$ when the sample volume was $20 \mathrm{~mL}$. The sample was continuously mixed at a low speed with a micro stirring rod to avoid vortex formation. The incident UV intensity was measured by a radiometer (International Light IL 1400 A, MA, USA,) immediately before UV light irradiation on the sample.

\subsection{Washed DFC-MIP Particles}

The DFC-MIP particles were washed in DDW with ultrasonication for $15 \mathrm{~min}$ to remove free DFC and prepolymerization residues. After 3 or 6 times of washing, 
the proper concentration needed was obtained by suspension of the particles in a calculated volume of DDW.

\subsection{Effect of Hydrochloric Acid on DFC}

The stability of DFC (50 ppm) was examined in various concentrations of hydrochloric acid $(0.025-125 \mathrm{mM})$ for different time periods (0.5 - 120 hours) at room temperature. Similarly, the degradation effect of hydrochloric acid on DFC in MIP particles was also studied.

\section{Results and Discussion}

\subsection{Characterization of DFC-MIP Particles}

After preparation, the size of DFC-MIP particles was measured in an aqueous suspension by dynamic light scattering (DLS). DLS was useful for perceiving the size-dependent diffusion behavior of polymer particles in aqueous suspension. The average diameter $(\mathrm{n}=10)$ was $0.7 \pm 0.2 \mu \mathrm{m}$. The DFC-MIP particles were also examined under a scanning electron microscope (SEM). Their SEM image (in Figure 1) showed dry particles with an average diameter of $0.3 \pm 0.1 \mu \mathrm{m}$.

The UV-visible spectrum of a DFC solution exhibited maximum absorbance at $276 \mathrm{~nm}$ (in Figure 2). An aqueous suspension of DFC-MIP particles also showed a clear
DFC peak at the same wavelength. However, an aqueous suspension of NIP particles did not show any peak since they did not consist of any DFC. Absorption (and scattering) of light was a size-, shape- and material-dependent characteristic of the particles. The absorption of UV light energy below $250 \mathrm{~nm}$ resulted in opacity that, fortunately, did not hinder the spectrophotometric determination of DFC (at $276 \mathrm{~nm}$ ) or the degradation of DFC by UV light (at $253.7 \mathrm{~nm}$ ).

\subsection{Degradation of DFC by UV Irradiation}

Irradiation by UV light is a method commonly used to degrade DFC and other pharmaceuticals in water, without the addition of chemicals. It is well known that passing water through a beam of UV light breaks down DFC as well as other organic compounds in the water. The extent of the degradation depends on the UV light wavelength and UV dose. A wavelength of $185 \mathrm{~nm}$ effectively breaks down and oxidizes carbon-containing molecules [34], yielding ionized fragments that can be subsequently removed by ion exchange. In the present study, UV irradiation experiments were conducted using low-pressure mercury lamps that emit monochromatic UV light at $253.7 \mathrm{~nm}$. The DFC standard solution, DFC-MIP suspension and NIP suspension were exposed to UV light (either 300 or $600 \mathrm{~mJ} / \mathrm{cm}^{2}$ ) to investigate the degradation

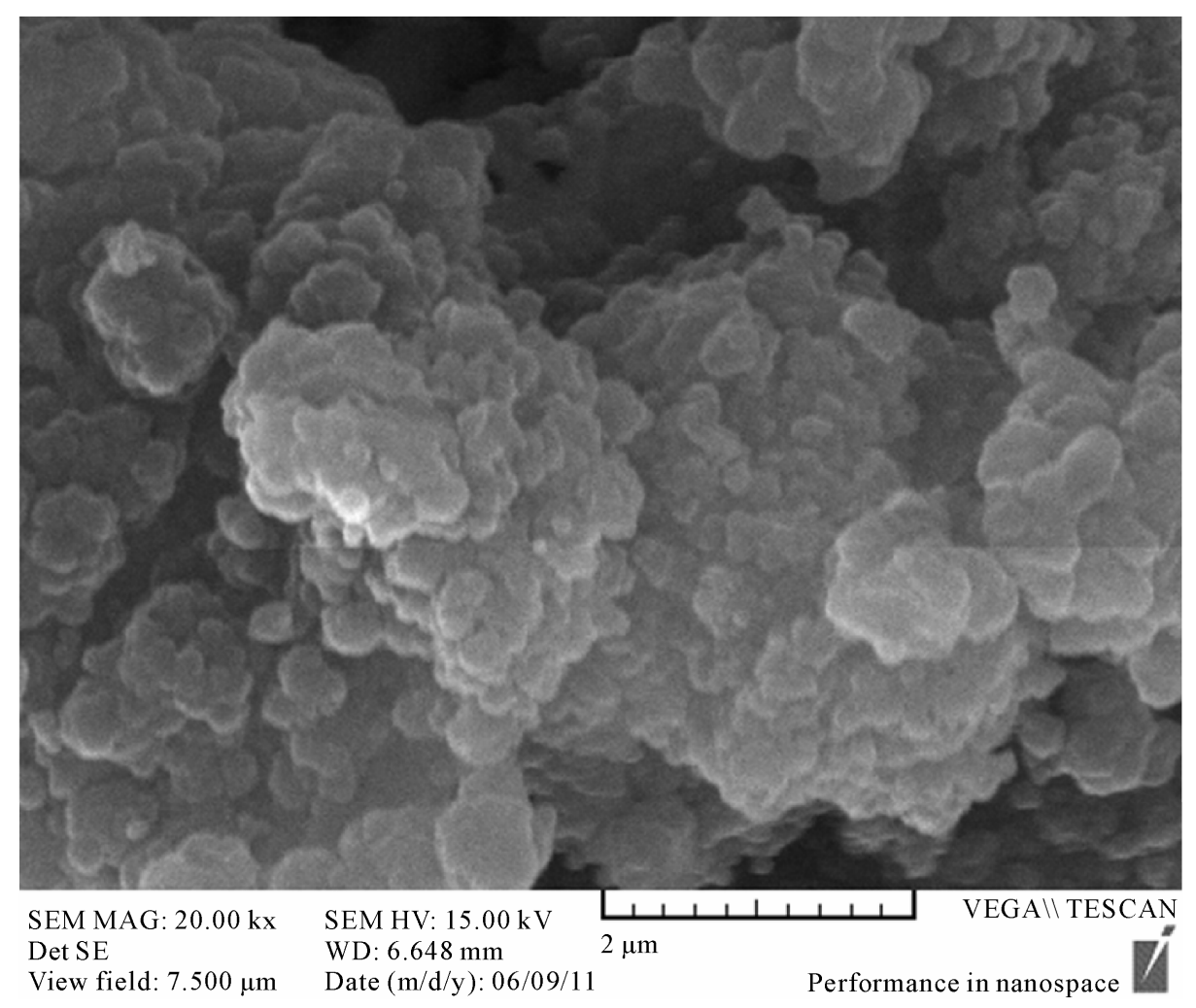

Figure 1. SEM image of DFC-MIP particles. 


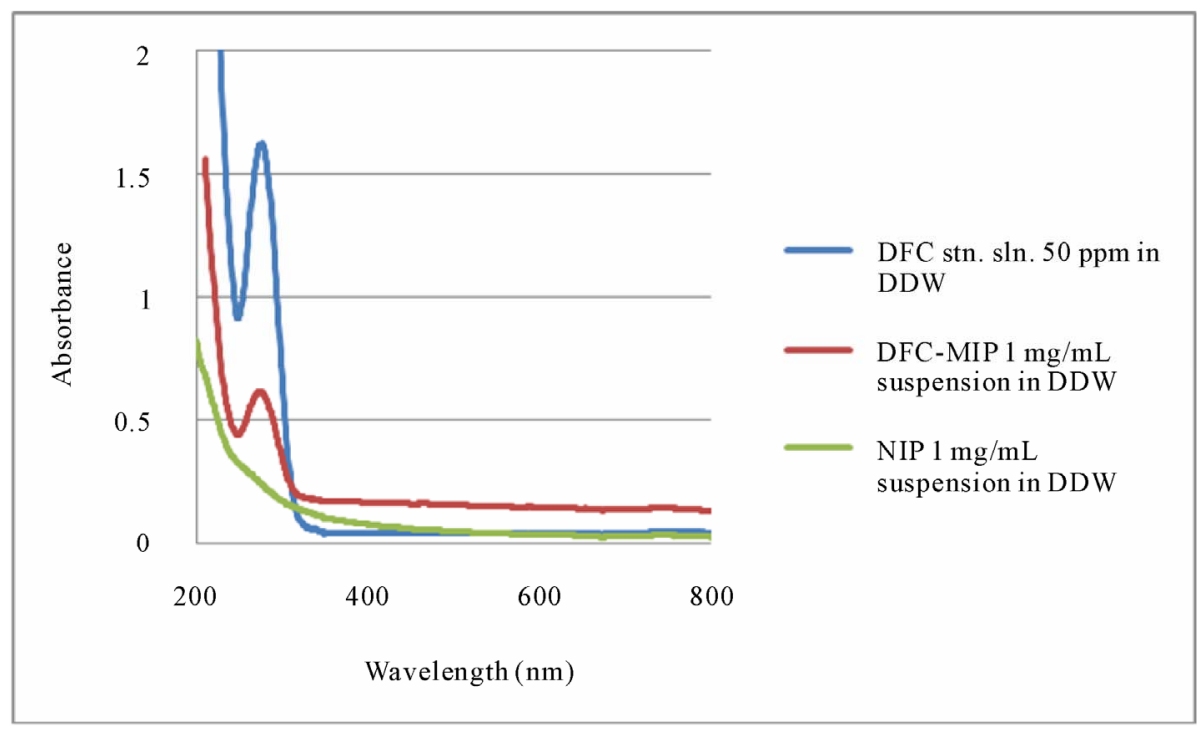

Figure 2. UV-visible absorption spectra of DFC standard solution (50 ppm), DFC-MIP suspension (1 mg/mL), and NIP suspension (1 $\mathrm{mg} / \mathrm{mL})$.

of DFC. As shown by the UV-visible absorption spectra in Figure 3, absorbance at $254 \mathrm{~nm}$ of the NIP suspension did not change after exposure to UV light. For both the DFC standard solution and DFC-MIP suspension, their absorbance values at $254 \mathrm{~nm}$ increased (by $245 \%$ and $130 \pm 7 \%$ respectively). Their colors also changed to yellowish due to the formation of a degradation product. No peak was observed at $276 \mathrm{~nm}$ ( $\lambda_{\max }$ for DFC). As no difference was observed between $600 \mathrm{~mJ} / \mathrm{cm}^{2}$ and 300 $\mathrm{mJ} / \mathrm{cm}^{2}$, DFC degradation was completed by exposure to either UV light dose. In a previous study, DFC was analyzed by RP-HPLC after reaction with OH free radicals that were obtained by exposing a mixture of DFC, ferrous sulphate and ascorbic acid to tungsten lamp irradiation. The chromatographic profiles showed the formation of several new peaks due to degradation/oxidation products [35]. A degradation product was determined by RPHPLC to be 1-(2,6-dichlorophenyl)-indolin-2-one [36]. Another study proposed a reaction path (via hydroxylation, dehalogenation, cleavage of the NH-bridge between the aromatic rings, subsequent oxidative ring opening and stepwise degradation) leading to carboxylic acids [37].

\subsection{Preconcentration of DFC by MIP Particles before UV Irradiation}

MIP particles were used to pre-concentrate DFC in water before UV light irradiation. The $\mathrm{pK}_{\mathrm{a}}$ of $\mathrm{DFC}$ was 4.1; therefore, DFC was negatively charged due to ionization in the normal range of $\mathrm{pH} 6.5$ to 8.5 in surface water systems. Similarly, the $\mathrm{pK}_{\mathrm{a}}$ of MAA is 4.66 , indicating that the MIP surface could be negatively charged. Hy- drogen bonding and hydrophobic interactions is expected to play an important role in overcoming the electrostatic repulsive interactions between DFC and the MIP suggesting that other interactions such as hydrogen bonding and hydrophobic interaction were still involved in the sorption process during preconcentration. This finding is inconsistent with previous results that the electrostatic interaction played an important role in recognizing the target compound in the sorption process [38]. After the MIP particles were separated from water using centrifugation, no significant amount of DFC was found in the centrate. When the particles were next exposed to UV light irradiation, any undesirable yellowish coloration due to degradation products would not cause any contamination of the decanted water. It the MIP particles were added to water after UV light irradiation, they would remove any remaining amount of DFC as well as all degradation products in the water. After centrifugation to separate the particles, the supernatant water would be depleted of DFC and degradation products (with concomitant disappearance of the undesirable yellowish coloration).

\subsection{Degradation of DFC by Hydrochloric Acid}

The stability of DFC in aqueous solution was examined in the presence of various concentrations of hydrochloric acid $(0.025$ to $125 \mathrm{mM})$. Although DFC was not degraded significantly in the $0.025 \mathrm{M}$ hydrochloric acid solution, it was largely degraded in hydrochloric acid solutions stronger than $0.125 \mathrm{mM}$ (see Figure 4(a) and 4(b)).

Figure 4 shows the effect of $\mathrm{HCl}$ on the degradation 


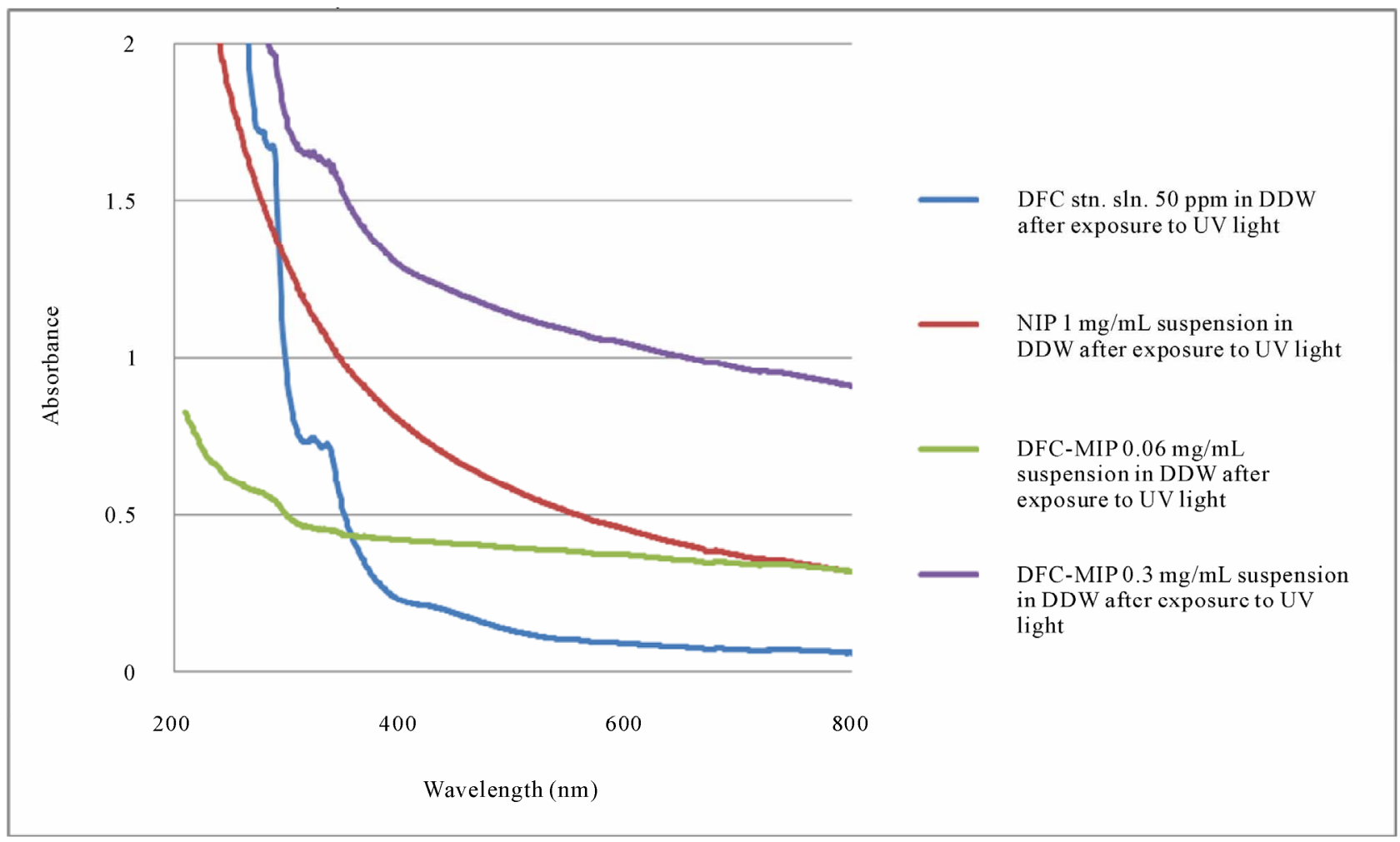

Figure 3. UV-visible absorption spectra of DFC standard solution (50 ppm), DFC-MIP suspension, and NIP suspension after exposure to UV light.

of DFC in water. The efficiency was close to $100 \%$, and it remained unchanged as the $\mathrm{HCl}$ concentration varied from $1 \mathrm{mM}$ to $125 \mathrm{mM}$ (i.e., solution $\mathrm{pH}$ varied from 3.0 to 0.9 ). The amount of DFC degraded in various concentrations of hydrochloric acid was examined over different periods of time (after 0.5, 24 and 72 hours) in Figure 5. Also, degradation of DFC in $0.125 \mathrm{mM}$ hydrochloric acid was examined over the treatment periods (from 0.5 to 120 hours) in Figure 6. The DFC was considerably $(75 \pm 1 \%)$ degraded by $0.125 \mathrm{mM} \mathrm{HCl}$ even after 0.5 hour. These results show that degradation of DFC in hydrochloric acid media can be efficient, depending on the acid concentration as well as the treatment time.

\subsection{Regeneration of MIP}

Regeneration of MIP was also investigated. Degradation of DFC by $\mathrm{HCl}$ was both efficient and rapid. However, there was no re-binding of DFC by the MIP particles after $\mathrm{HCl}$ treatment (and DDW washing) when exposed to DFC for 24 hours. One possible reason for this is the degradation product left behind inside the binding cavities. However, DFC seemed to be an ionic species that has a high solubility in water. Therefore the particles were washed with DDW three to six times, after which the amount of DFC remaining was determined by UV- visible spectrophotometry. As shown in Figure 7, our MIP particles were regenerated by washing with DDW. These MIP particles could either bind DFC in water, or let DFC washed out by water, depending on the concentration. When the particles with no DFC (after UV exposure) were exposed to a DFC solution of $50 \mathrm{ppm}$, the DFC rebound with MIP. After rebinding, when the particles were washed with DDW, the bound DFC left the particles to reach new partition equilibrium.

To examine the binding efficiency of the MIP particles after regeneration, the regenerated MIP particles were mixed with a DFC standard solution for 24 hours. UVvisible spectroscopy was used to determine the amount of DFC re-bound onto the particles, as shown in Figure 8(a). A comparison of the absorption spectra between the generated MIP particles after rebinding DFC (considering the 10 times dilution) and the DFC standard solution (5 ppm) indicated that the MIP particles rebound a considerable amount of DFC (approximately $44 \mathrm{ppm}$ ). This $88 \%$ recovery of DFC was very satisfactory, considering the amount of DFC available for MIP binding was 50 ppm (which was an arbitrarily high concentration needed to accommodate the modest sensitivity of UV-visible spectrophotometry). In Figure 8(b), the last UV-visible spectrum was obtained for the supernatant after the MIP particles rebound with DFC and washed three times. It 


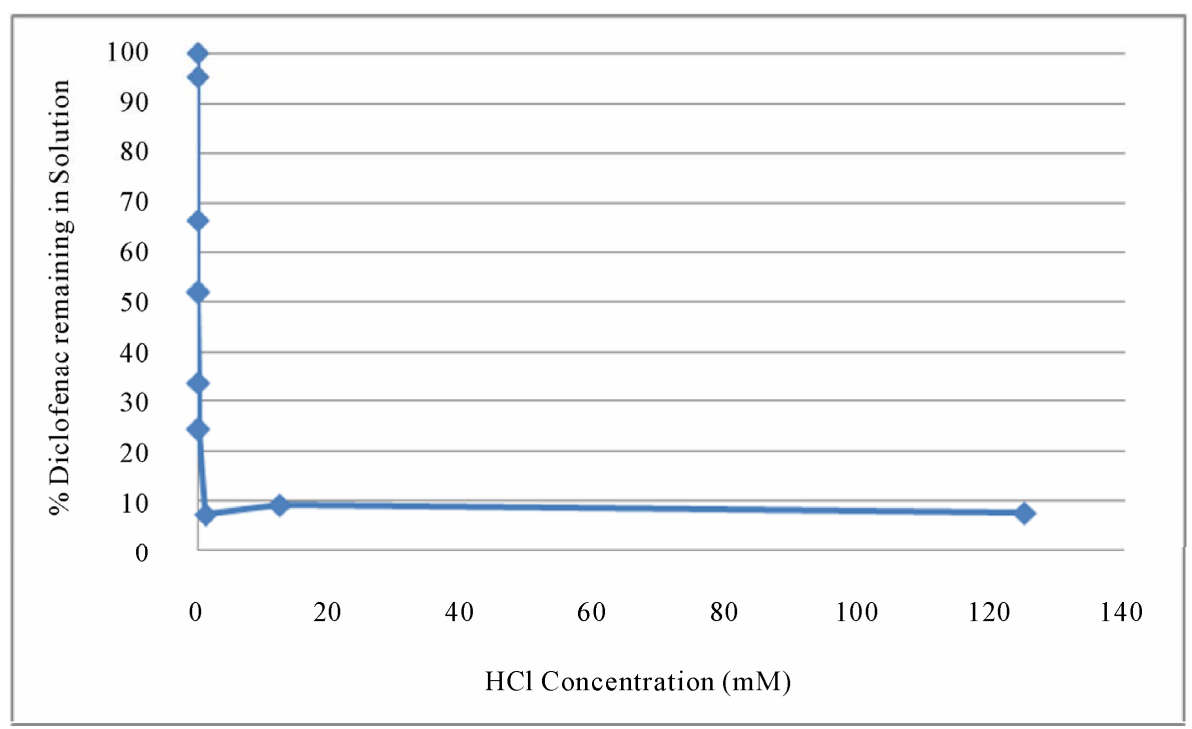

(a)

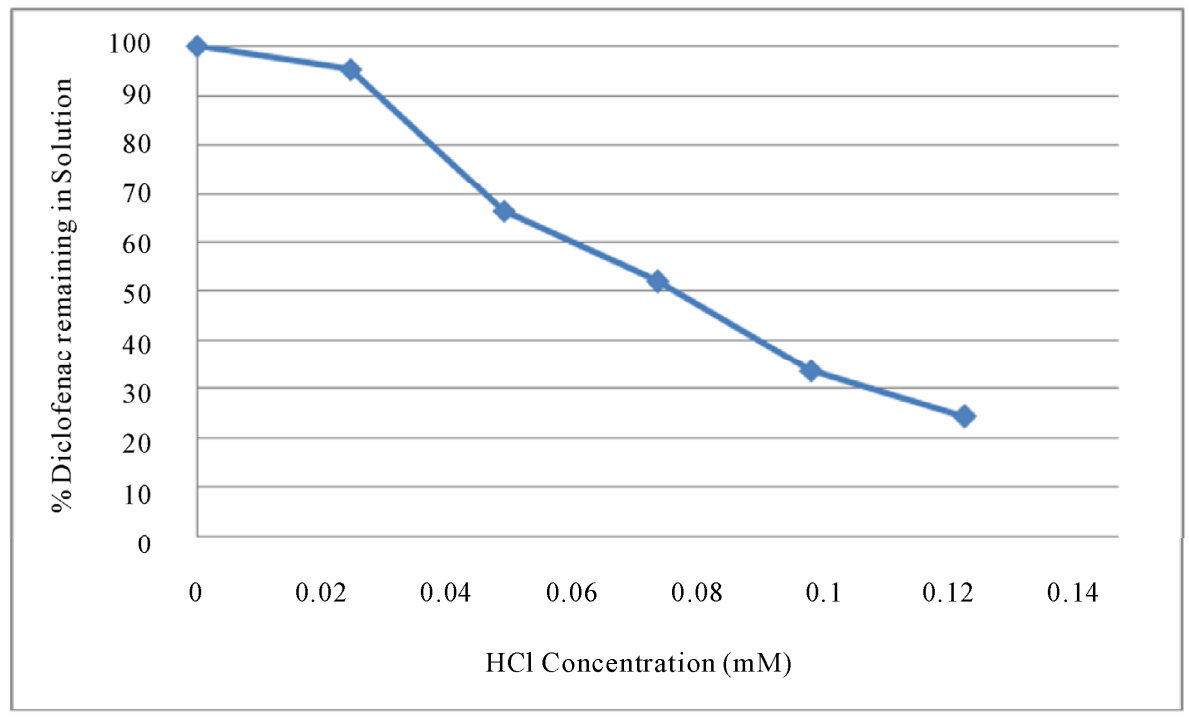

(b)

Figure 4. \% DFC remaining in hydrochloric acid solution (a) in 0.025 to $125 \mathrm{mM}$, and (b) in 0.025 to $0.125 \mathrm{mM}$ after 72 hours.

showed all DFC was removed from the particles. The demonstrated reusability and easy regeneration of MIP particles over several adsorption and desorption cycles is very advantageous and opens a possibility for larger scale applications such as water and wastewater treatment.

\subsection{Non-Specific Binding of MIP}

Because pharmaceuticals in the aquatic environment occur usually as mixtures, an accurate prediction of the mixture toxicity is indispensable for environmental risk assessment. The ecotoxicity of the non-steroidal anti- inflammatory drugs (NSAIDs) DFC, ibuprofen, naproxen, and acetylsalicylic acid (ASA) was previously evaluated using acute Daphnia and algal tests [39]. In four countries (France, Greece, Italy, and Sweden) occurrence in sewage treatment plant (STP) effluents and ecotoxicity of the pharmaceuticals DFC, carbamazepine and clofibric acid were investigated [40]. The wavelength of maximum absorption for ibuprofen is $264 \mathrm{~nm}$, for carbamazepine $284 \mathrm{~nm}$, and for clofibric acid $284 \mathrm{~nm}$. The impact of these other pharmaceutical compounds, due to non-specific binding with the DFC-MIP particles, on UV irradiation and $\mathrm{HCl}$ treatment of $\mathrm{DFC}$ would require systematic investigation. 


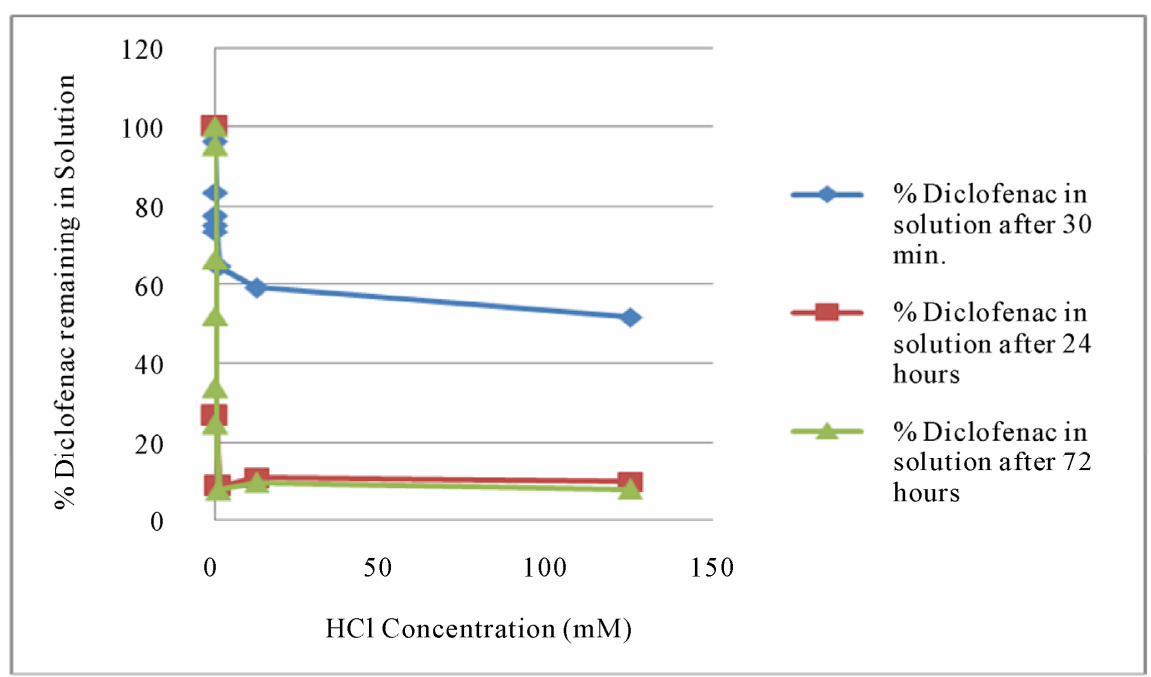

Figure 5. \% DFC remaining in various hydrochloric acid solutions (0.025 to $125 \mathrm{mM})$ after 0.5, 24 and 72 hours.

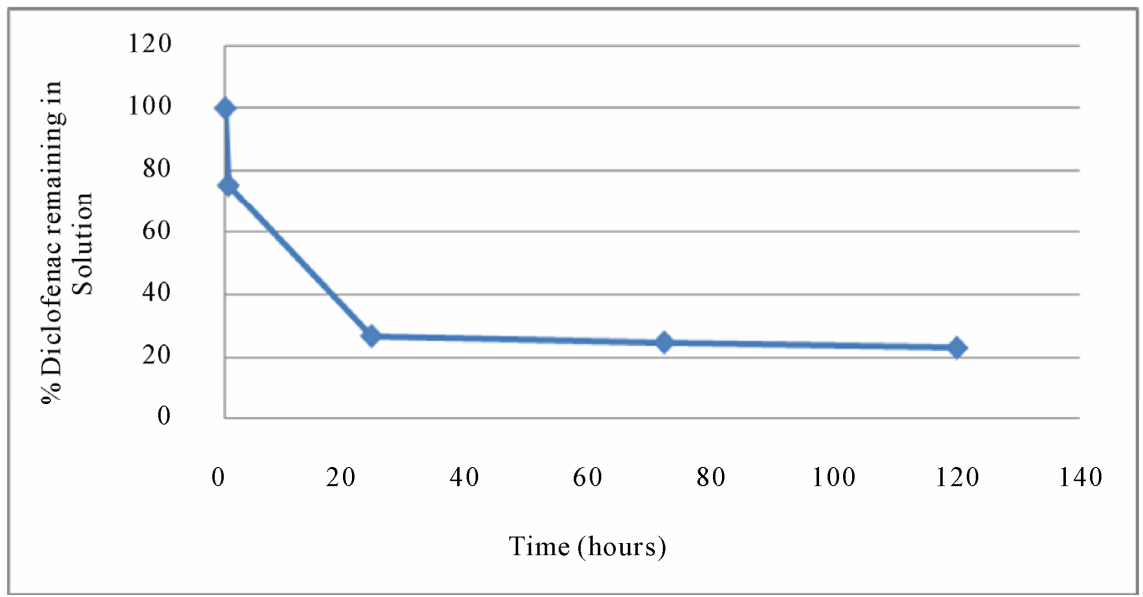

Figure 6. \% DFC remaining in $0.125 \mathrm{mM}$ hydrochloric acid solution after different treatment times.

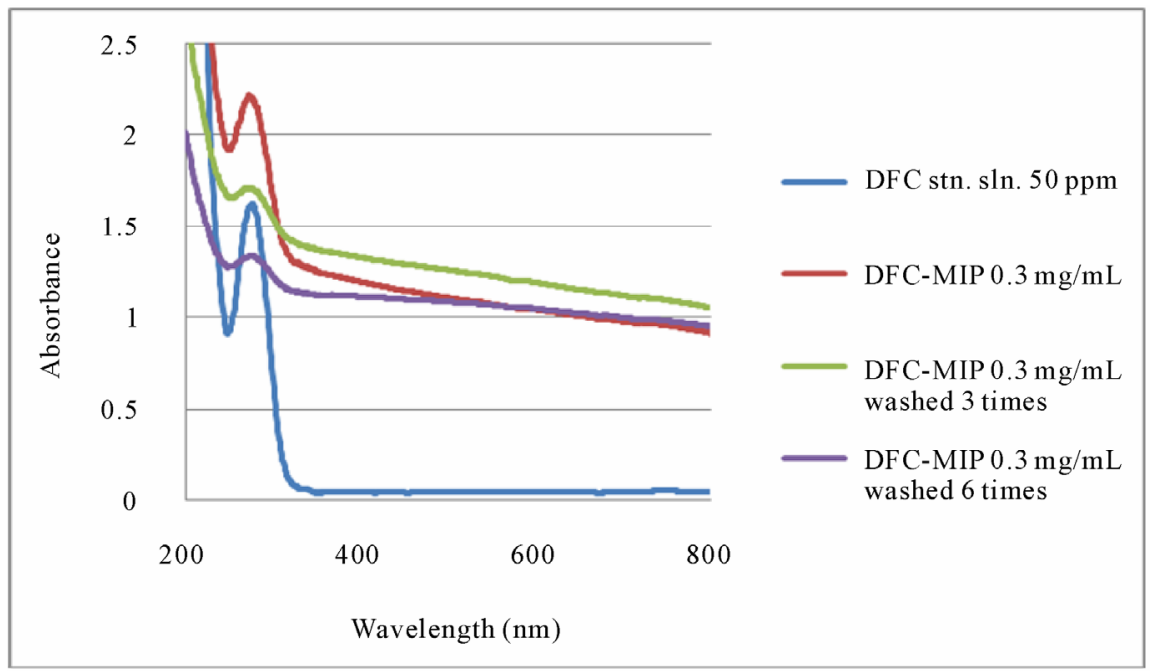

Figure 7. UV-visible absorption spectra of DFC standard solution (50 ppm), DFC-MIP suspension, DFC-MIP (washed with DDW 3 times) suspension, and DFC-MIP (washed with DDW 6 times) suspension. 


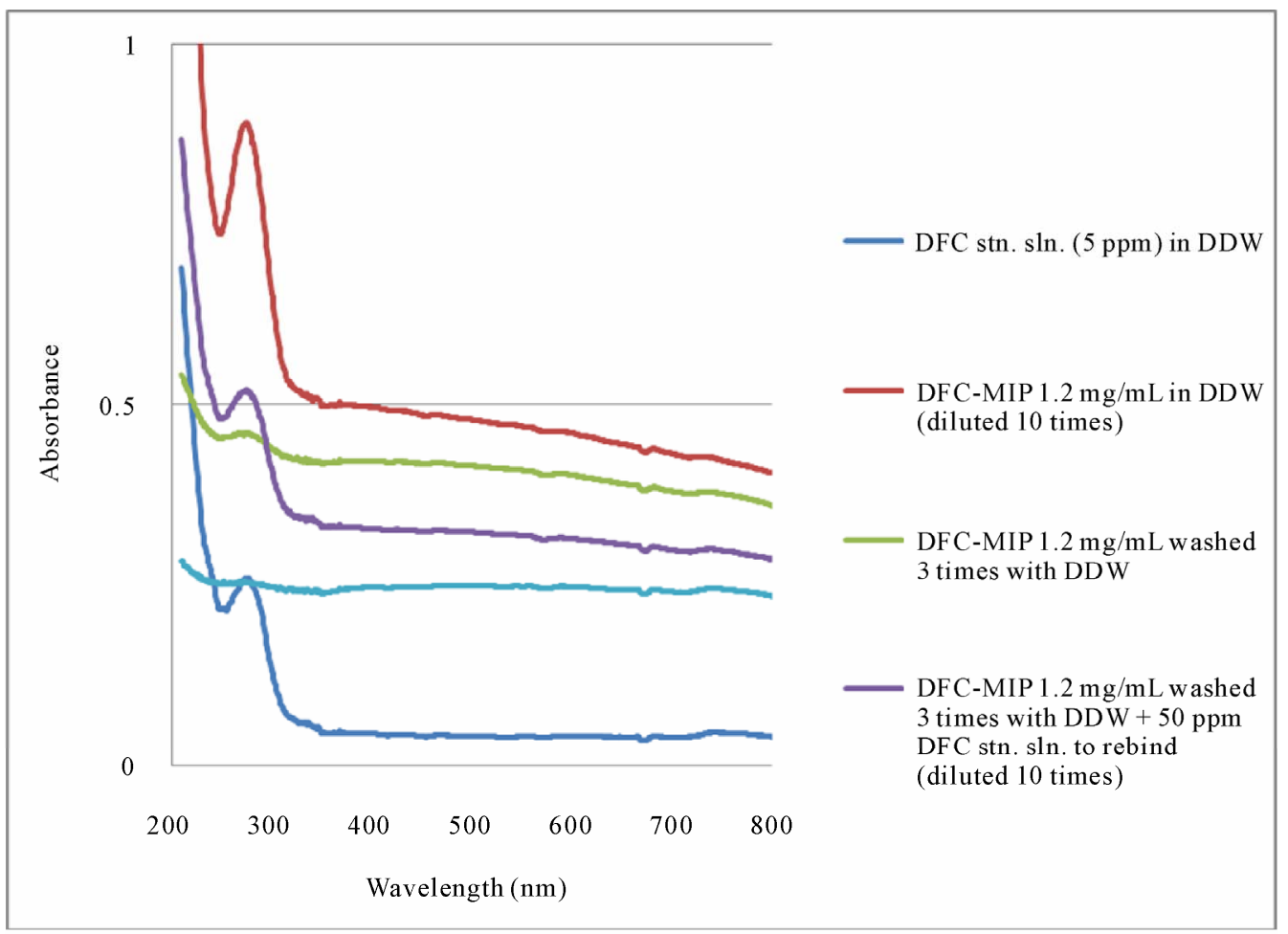

(a)

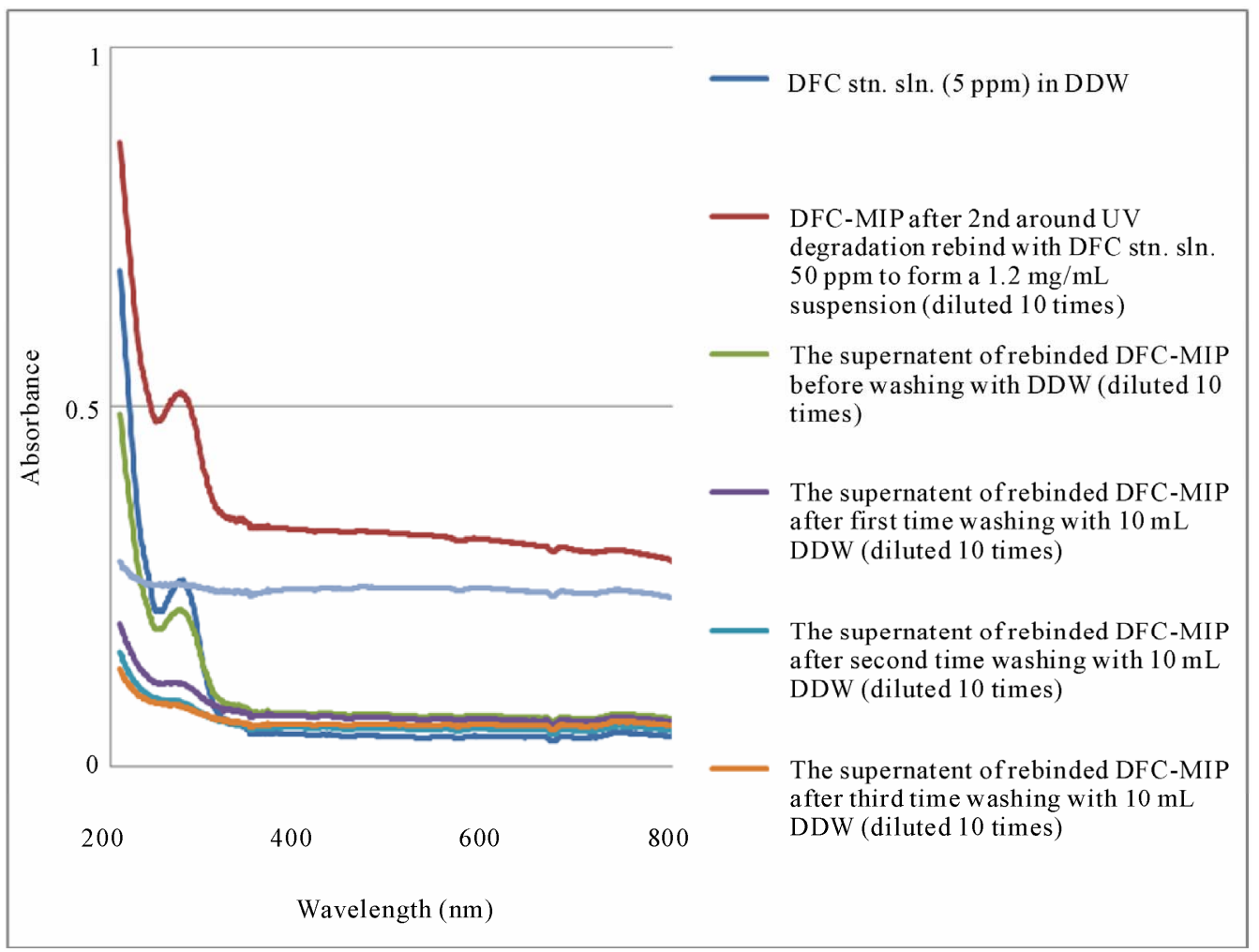

(b)

Figure 8. (a) UV-visible absorption spectra of DFC standard solution, DFC-MIP suspension, and DFC-MIP (washed 3 times) suspension, before and after rebinding with DFC, and (b) UV-visible absorption spectra of DFC standard solution, DFC-MIP suspension, DFC-MIP (washed 3 times) suspension, before and after rebinding with DFC, as well as the final supernatant. 


\section{Conclusions}

The present work demonstrated that the molecular imprinting process can produce polymer materials that have a wide variety of applications in environmental chemistry, specifically well suited for the degradation of DFC by UV light irradiation and $\mathrm{HCl}$ acid treatment. Previously, only the sol-gel process was known to produce inorganic (such as siloxane) polymer materials with optical transparency, chemical inertness, rigidity and porosity that make them ideally suited for specialized applications (such as photo-degradation) [41]. Future work would require the development of a sensitive, selective and accurate liquid chromatography-mass spectrometry (LC-MS) assay for the determination of DFC sodium. A good mobile phase for DFC elution may consist of acetonitrile and $20 \mathrm{mM}$ ammonium acetate solution $(5: 1 \mathrm{v} / \mathrm{v})$ at pH 7.4 [42]. Liquid chromatography-triple quadrupole mass spectrometric assay would be needed for the simultaneous determination of DFC and other pharmaceuticals in water [43]. An ultra-performance LC-MS method would have to be employed for the separation, detection and identification of the many metabolites and transformation products of DFC (using a common diagnostic fragment ion at $\mathrm{m} / \mathrm{z} 214$ ) [44].

\section{Acknowledgements}

EPCL thanks Natural Sciences and Engineering Research Council (NSERC) Canada for continuous financial support of his MIP program and many operating lab facilities at Carleton University. This work is partially supported by the Canadian Water Network as Innovative Treatment Technologies.

\section{References}

[1] S. Mompelat, B. Le Bot and O. Thomas, "Occurrence and Fate of Pharmaceutical Products and By-products, from Resource to Drinking Water," Environment International, Vol. 35, No. 5, 2009, pp. 803-814. doi:10.1016/j.envint.2008.10.008

[2] M. Letzel, G. Metzner and T. Letzel, "Exposure Assessment of the Pharmaceutical Diclofenac Based on Long-Term Measurements of the Aquatic Input," Environment International, Vol. 35, No. 1, 2009, pp. 363-368.

[3] X. F. Zhou, C. M. Dai, Y. L. Zhang, R. Surampalli and T. Zhang, "A Preliminary Study on the Occurrence and Behavior of Carbamazepine (CBZ) in Aquatic Environment of Yangtze River Delta, China," Environmental Monitoring and Assessmen, Vol. 173, 2010, pp. 45-53.

[4] British Pharmacopoeia, International Ed. HMSO Publication, London, Vol. I, 2004, p. 469.

[5] The United State Pharmacopoeia, 29th Ed. United States
Pharmacopoeial Convention, Inc., Rockville, MD 206, 2005, p. 683.

[6] Indian Pharmacopoeia, 6th Ed. Government of India, The Controller of Publications, New Delhi, Vol. III, 2010, p. 2213.

[7] http://www.chemicalland21.com/lifescience/phar/DICLO FENAC.htm

[8] M. Janbroers, "Review of the Toxicology, Pharmacodynamics and Pharmacokinetics of Thiocolchicoside, a GABA-Agonist Muscle Relaxant with Antinflammatory and Analgesic Action," Acta Ther., Vol. 13, 1987, pp. 221-225.

[9] V. Naddeo, V. Belgiorno, D. Ricco and D. Kassinos, "Degradation of Diclofenac during Sonolysis, Ozonation and Their Simultaneous Application," Ultrasonics Sonochemistry, Vol. 16, No. 6, 2009, pp. 790-794. doi:10.1016/j.ultsonch.2009.03.003

[10] D. Stülten, S. Zühlke, M. Lamshöft and M. Spiteller, "Occurrence of Diclofenac and Selected Metabolites in Sewage Effluents," Science of the Total Environment, Vol. 405, No. 1-3, 2008, pp. 301-310.

[11] M. Letzel, G. Metzner and T. Letzel, "Exposure Assessment of the Pharmaceutical Diclofenac Based on Long-Term Measurements of the Aquatic Input," Environment International, Vol. 35, No. 2, 2009, pp. 363-368.

[12] H. Ericson, G. Thorsén and L. Kumblad, "Physiological Effects of Diclofenac, Ibuprofen and Propranolol on Baltic Sea Blue Mussels," Aquatic Toxicology, Vol. 99, No. 2, 2010, pp. 223-231. doi:10.1016/j.aquatox.2010.04.017

[13] G. Swan, V. Naidoo, R. Cuthbert, R. E. Green, D. J. Pain, D. Swarup, V. Prakash and K. Wolter, "Removing the Threat of Diclofenac to Critically Endangered Asian Vultures," PLoS Biology, Vol. 4, No. 3, 2006, p. e66. doi:10.1371/journal.pbio.0040066

[14] V. Naidoo and G. E. Swan, "Diclofenac Toxicity in Gyps Vulture is Associated with Decreased Uric Acid Excretion and Not Renal Portal Vasoconstriction," Comparative Biochemistry and Physiology Part C: Toxicology \& Pharmacology, Vol. 149, No. 3, 2009, pp. 269-274. doi:10.1016/j.cbpc.2008.07.014

[15] P. Calza, V. A. Sakkas, C. Medana, C. Baiocchi, A. Dimou, E. Pelizzetti and T. Albanis, "Photocatalytic Degradation Study of Diclofenac over Aqueous $\mathrm{TiO}_{2}$ Suspensions," Applied Catalysis B: Environmental, Vol. 67, No. 3-4, 2006, pp. 197-205. doi:10.1016/j.apcatb.2006.04.021

[16] J. Hofmann, U. Freier, M. Wecks and S. Hohmann, "Degradation of Diclofenac in Water by Heterogeneous Catalytic Oxidation with $\mathrm{H}_{2} \mathrm{O}_{2}$," Applied Catalysis $B$ : Environmental, Vol. 70, No. 1-4, 2007, pp. 447-451. doi:10.1016/j.apcatb.2005.11.023

[17] A. Ghauch, H. Abou Assi and S. Bdeir, "Aqueous Removal of Diclofenac by Plated Elemental Iron: Bimetallic Systems," Journal of Hazardous Materials, Vol. 182, No. 1-3, 2010, pp. 64-74. 
doi:10.1016/i.jhazmat.2010.05.139

[18] A. Achilleosa, E. Hapeshia, P. X. Nikolaos, D. Mantzavinosb and D. Fatta-Kassinosa, "Factors Affecting Diclofenac Decomposition in Water by UV-A/TiO 2 Photocatalysis," Chemical Engineering Journal, Vol. 161, No. 1-2, 2010, pp. 53-59. doi:10.1016/j.cej.2010.04.020

[19] G. Laera, M. N. Chong, B. Jin and A. Lopez, “An Integrated $\mathrm{MBR}-\mathrm{TiO}_{2}$ Photocatalysis Process for the Removal of Carbamazepine from Simulated Pharmaceutical Industrial Effluent," Bioresource Technology, Vol. 102, No. 13, 2011, pp. 7012-7015. doi:10.1016/j.biortech.2011.04.056

[20] J. Madhavan, P.S.S. Kumar, S. Anandan, M. Zhou, F. Grieser and M. Ashokkumar, "Ultrasound Assisted Photocatalytic Degradation of Diclofenac in an Aqueous Environment," Chemosphere, Vol. 80, 2010, pp. 747-752.

[21] F. R. Slater, A. C. Singer, S. Turner, J. J. Barr and P. L. Bond, "Pandemic Pharmaceutical Dosing Effects on Wastewater Treatment," FEMS Microbiology Letters, Vol. 315, No. 1, 2011, pp. 17-22. doi:10.1111/j.1574-6968.2010.02163.x

[22] C. Zwiener and F. H. Frimmel, "Short-Term Tests with a Pilot Sewage Plant and Biofilm Reactors for the Biological Degradation of the Pharmaceutical Compounds Clofibric Acid, Ibuprofen, and Diclofenac," The Science of the Total Environment, Vol. 309, 1-3, 2003, pp. 201-211. doi:10.1016/S0048-9697(03)00002-0

[23] E. Marco-Urrea, M. Pérez-Trujillo, C. Cruz-Morató, G. Caminal and T. Vicent, "Degradation of the Drug Sodium Diclofenac by Trametes Versicolor Pellets and Identification of Some Intermediates by NMR," Journal of Hazardous Materials, Vol. 176, No. 1-3, 2010, pp. 836-842. doi:10.1016/j.jhazmat.2009.11.112

[24] Y. Zhang and S. U. Geißen, "In Vitro Degradation of Carbamazepine and Diclofenac by Crude Lignin Peroxidase," Journal of Hazardous Materials, Vol. 176, No. 1-3, 2010, pp. 1089-1092. doi:10.1016/j.jhazmat.2009.10.133

[25] V. Naddeo, V. Belgiorno, D. Kassinos, D. Mantzavinos and D. Meric, "Ultrasonic Degradation, Mineralization and Detoxification of Diclofenac in Water: Optimization of Operating Parameters," Ultrasonics Sonochemistry, Vol. 17, No. 1, 2010, pp. 179-185. doi:10.1016/j.ultsonch.2009.04.003

[26] J. Hartmann, P. Bartels, U. Mau, M. Witter, W. V. Tümpling, J. Hofmann and E. Nietzschmann, "Degradation of the Drug Diclofenac in Water by Sonolysis in Presence of Catalysts," Chemosphere, Vol. 70, No. 3, 2008, pp. 453461. doi:10.1016/j.chemosphere.2007.06.063

[27] G. T. Güyer and N. H. Ince, "Degradation of Diclofenac in Water by Homogeneous and Heterogeneous Sonolysis," Ultrasonics Sonochemistry, Vol. 18, No. 1, 2011, pp. 114-119. doi:10.1016/j.ultsonch.2010.03.008

[28] N. J. Mamouzelos, C. S. Proikakis, P. A. Tarantili and A. G. Andreopoulos, "Release of Propranolol and Diclofenac from Low Molecular Weight DL-Poly(Lactic Acid)," Journal of Biomaterials Applications, Vol. 16, No. 3, 2002, pp. 177-190.
[29] M. D. Kurkuri and T. M. Aminabhavi, "Poly(Vinyl Alcohol) and Poly(Acrylic Acid) Sequential Interpenetrating Network pH-Sensitive Microspheres for the Delivery of Diclofenac Sodium to the Intestine," Journal of Controlled Release, Vol. 96, No. 1, 2004, pp. 9-20.

doi:10.1016/j.jconrel.2003.12.025

[30] C. M. Dai, S. U. Geissen, Y. L. Zhang, Y. J. Zhang and X. F. Zhou, "Selective Removal of Diclofenac from Contaminated Water Using Molecularly Imprinted Polymer Microspheres," Environmental Pollution, Vol. 159, No. 6, 2011, pp. 1660-1666. doi:10.1016/j.envpol.2011.02.041

[31] S. Wei, A. Molinelli and B. Mizaikoff, "Molecularly Imprinted Micro and Nanospheres for the Selective Recognition of 17 $\beta$-Estradiol," Biosensors and Bioelectronics, Vol. 21, No. 10, 2006, pp. 1943-1951.

doi:10.1016/j.bios.2005.09.017

[32] S. S. Qian, M. Donnelly, D. C. Schmelling, M. Messner, K. G. Linden and C. Cotton, "Ultraviolet Light Inactivation of Protozoa in Drinking Water: A Bayesian metaanalysis," Water Research, Vol. 38, No. 2, 2004, pp. 317-326. doi:10.1016/j.watres.2003.10.007

[33] H. J. Morowitz, "The Action of Ultraviolet Light and Ionizing Radiation on Spores of Bacillus Subtilis. I. The Ultraviolet Lethal Action, Mutation Action and Absorption Spectra," Archives of Biochemistry and Biophysics, Vol. 47, 2, 1953, pp. 325-337. doi:10.1016/0003-9861(53)90470-6

[34] H. P. Schuchmann, C. Von Sonntag and R. Srinivasan, "The UV Photolysis ( $\lambda=254$ and $185 / 254 \mathrm{~nm}$ ) of Cyclohexene in Oxygen-Saturated and Oxygen-Free Cyclopentane Solution," Journal of Photochemistry and Photobiology A: Chemistry, Vol. 45, 1988, p. 49. doi:10.1016/1010-6030(88)80115-1

[35] M.C. Gaudiano, L. Valvo, P. Bertocchi and L. Manna, "RP-HPLC Study of the Degradation of Diclofenac and Piroxicam in the Presence of Hydroxyl Radicals," Journal of Pharmaceutical and Biomedical Analysis, Vol. 32, No. 4, 2003, pp. 151-158. doi:10.1016/S0731-7085(03)00058-X

[36] R. Hájková, P. Solich, M. Pospíilová and J. Icha, "Simultaneous Determination of Methylparaben, Propylparaben, Sodium Diclofenac and Its Degradation Product in a Topical Emulgel by Reversed-Phase Liquid Chromatography," Analytica Chimica Acta, Vol. 467, No. 1-2, 2002, pp. 91-96.

[37] J. Hofmann, U. Freier, M. Wecks and S. Hohmann, "Degradation of Diclofenac in Water by Heterogeneous Catalytic Oxidation with $\mathrm{H}_{2} \mathrm{O}_{2}$," Applied Catalysis $B$ : Environmental, Vol. 70, No. 1-4, 2007, pp. 447-451. doi:10.1016/j.apcatb.2005.11.023

[38] Q. Yu, S. Deng and G. Yu, "Selective Removal of Perfluorooctane Sulfonate from Aqueous Solution Using Chitosan-Based Molecularly Imprinted Polymer Adsorbents," Water Research, Vol. 42, No. 12, 2008, pp. 3089-3097. doi:10.1016/j.watres.2008.02.024

[39] M. Cleuvers, "Mixture Toxicity of the Anti-inflammatory Drugs Diclofenac, Ibuprofen, Naproxen, and Acetylsali- 
cylic Acid," Ecotoxicology and Environmental Safety, Vol. 59, No. 3, 2004, pp. 309-315.

doi:10.1016/S0147-6513(03)00141-6

[40] B. Ferrari, N. Paxéus, R. L. Giudice, A. Pollio and J. Garric, "Ecotoxicological Impact of Pharmaceuticals Found in Treated Wastewaters: Study of Carbamazepine, Clofibric Acid, and Diclofenac," Ecotoxicology and Environmental Safety, Vol. 55, No. 3, 2003, pp. 359-370. doi:10.1016/S0147-6513(02)00082-9

[41] S.C. Lee and H. Chen "Preparation of Sol-Gel Molecularly Imprinted Polymer Based on Tetraethoxysilane for Recognize Sulfonamides," 2009.

http://www.ncu.edu.tw/ ncu7020/Files/Phd_Repord/97/2 $6 / \ldots$

[42] M. E. Abdel-Hamid, L. Novotny and H. Hamza, "Determination of Diclofenac Sodium, Flufenamic Acid, Indomethacin and Ketoprofen by LC-APCI-MS," Journal of
Pharmaceutical and Biomedical Analysis, Vol. 24, No. 4, 2001, pp. 587-594. doi:10.1016/S0731-7085(00)00444-1

[43] R.W. Sparidans, J. S. Lagas, A. H. Schinkel, J. H. M. Schellens and J. H. Beijnen, "Liquid ChromatographyTandem Mass Spectrometric Assay for Diclofenac and Three Primary Metabolites in Mouse Plasma," Journal of Chromatography B, Vol. 872, No. 1-2, 2008, pp. 77-82. doi:10.1016/j.jchromb.2008.07.012

[44] T. Kosjek, E. Heath, S. Pérez, M. Petrović and D. Barceló, "Metabolism Studies of Diclofenac and Clofibric Acid in Activated Sludge Bioreactors Using Liquid Chromatography with Quadrupole-Time-of-Flight Mass Spectrometry," Journal of Hydrology, Vol. 372, 2009, p. 109. 